\title{
PENENTUAN KRITERIA DALAM PEMILIHAN JENIS PERKERASAN PADA DATARAN TINGGI DI KABUPATEN TRENGGALEK
}

\author{
Anang Prayogo ${ }^{a}$, Hitapriya Suprayitno ${ }^{b}$ dan Herry Budianto ${ }^{c}$
}

\begin{abstract}
Road infrastructure at hilly area is highly needed and very important to support the economics stability in the district of Trenggalek. Road infrastructure becoming the most important nowadays for the people of Trenggalek especially for those who live in the highland. The problems recently happened until now is the road infrastructure in the district of Trenggalek especially in the highland are many damaged, not feasible and many more that requires to be restored. The type selection of the pavement that proper and suit for the highland in the district of Trenggalek is highly influenced by some criteria. And from some literature study we can draw conclusions in 6 (six) criteria those are, road user safety, road user amenities, cost of construction, ease of execution for the road construction, treatment of the road construction after the maintenance period expired and the availability of the materials. Then from interviewing the respondents that has experienced in the road construction especially in the highland of Trenggalek concluded 7 (seven) criteria those are, road user safety, road user amenities, cost of construction, situation and condition of the project location, treatment of the road construction after the maintenance period expired and the durability to the scouring water.
\end{abstract}

Keywords: road, pavement, criteria, hilly area, and Trenggalek

\begin{abstract}
Abstrak: Infrastruktur jalan di dataran tinggi sangat dibutuhkan dan penting untuk menunjang perekonomian Kabupaten Trenggalek. Infrastruktur jalan menjadi hal yang sangat penting bagi masyarakat Trenggalek terutama di daerah dataran tinggi. Permasalahan yang terjadi, infrastruktur jalan yang ada di Kabupaten Trenggalek khususnya di dataran tinggi banyak mengalami kerusakan, tidak layak dan masih banyak memerlukan penanganan. Pemilihan tipe perkerasan yang tepat pada dataran tinggi di Kabupaten Trenggalek sangat dipengaruhi beberapa kriteria. Dari beberapa studi literatur didapatkan 6 kriteria diantaranya keselamatan penguna jalan, kenyamanan pengguna jalan, biaya konstruksi, kemudahan pelaksanaan konstruksi jalan, perawatan setelah masa pemeliharaan jalan habis dan ketersediaan material. Kemudian dari wawancara dengan responden yang memiliki pengalaman dalam penanganan jalan khususnya pada dataran tinggi di Kabupaten Trenggalek didapatkan 7 kriteria yaitu; keselamatan pengguna jalan, kenyamanan pengguna jalan, biaya konstruksi, situasi dan kondisi lokasi pekerjaan, perawatan setelah masa pemeliharaan jalan habis dan ketahanan terhadap gerusan air.
\end{abstract}

Kata Kunci: jalan, perkerasan, kriteria, dataran tinggi, dan Trenggalek

\section{PENDAHULUAN}

Trenggalek merupakan salah satu Kabupaten di Jawa Timur yang terletak di pesisir laut selatan, yang berbatasan langsung dengan Kabupaten Ponorogo, Kabupaten Tulungagung, Kabupaten Pacitan dan Kabupaten Wonogiri. Kondisi geografis di Kabupaten Trenggalek mayoritas didominasi oleh dataran tinggi. Dataran tinggi di Kabupaten Trenggalek berupa perbukitan. Di wilayah perbukitan terdapat infrastruktur jalan yang merupakan akses masyarakat untuk melakukan perpindahan dari satu tempat ke tempat yang lain dan untuk mendistribusikan hasil bumi. Kabupaten Trenggalek memiliki 14 Kecamatan dengan 153 desa dan 4 kelurahan. Oleh pemerintah daerah Kabupaten Trenggalek dari ke 14 kecamatan ini diklasifikasikan menjadi dua wilayah yaitu dataran tinggi dan dataran rendah. Sebagian besar dataran tinggi ada di 8 kecamatan

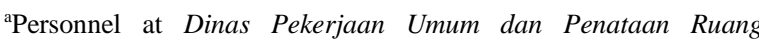
Kabupaten Trenggalek and a student in the Department of Civil Engineering, Sepuluh Nopember Institute of Technology (ITS), ITS Campus, Sukolilo, Surabaya 60111, Indonesia. Email: prayogoanang@yahoo.co.id

${ }^{b, c}$ Lecturer in the Department of Civil Engineering, Sepuluh Nopember Institute of Technology (ITS), ITS Campus, Sukolilo, Surabaya 60111, Indonesia. Email: suprayitno.hita@gmail.com, budiantoherry@yahoo.com

Note. The manuscript for this paper was submitted for review and possible publication on January 08, 2018. This paper is part of the ITS Journal of Civil Engineering, Vol. 33, No. 1, May 2018. (C) ITS Journal of Civil Engineering, ISSN 2579-9029/2017. dan dataran rendah ada di 6 kecamatan. Pengelompokan dataran rendah dan dataran tinggi ini didasarkan pada ketinggian dari permukaan air laut dan jalan yang dilalui. Mayoritas dataran tinggi berada di daerah pegunungan dan perbukitan. Pengelompokan ini bertujuan untuk memperhitungkan biaya pembangunan, pemeliharaan dan jenis konstruksi infrastruktur di Kabupaten Trenggalek.

Infrastruktur jalan di dataran tinggi sangat dibutuhkan dan penting untuk menunjang perekonomian Kabupaten Trenggalek. Dataran tinggi di Kabupaten Trenggalek memiliki tanah yang subur sehingga mayoritas penduduk di daerah pegunungan/dataran tinggi berprofesi sebagai petani dan pekebun. Hasil bumi dijadikan bahan baku dan banyak yang dijual di luar wilayah Trenggalek bahkan ada yang diekspor ke mancanegara, begitu juga dengan hasil lautnya. Sehingga infrastruktur jalan menjadi hal yang sangat penting bagi masyarakat Trenggalek terutama di daerah pegunungan/dataran tingi. Permasalahan yang terjadi, infrastruktur jalan yang ada di Kabupaten Trenggalek khususnya di dataran tinggi banyak terjadi kerusakan, tidak layak dan masih banyak memerlukan penanganan.

Kerusakan yang terjadi bisa disebabkan oleh pemilihan tipe perkerasan yang kurang tepat, karena topografi jalan dan topografi di wilayah dataran tinggi Kabupaten Trenggalek. Di sisi lain pemilihan tipe perkerasan yang kurang tepat dapat mengganggu keselamatan dan kenyamanan pengguna jalan. Selain itu proses pengerjakan yang sulit dan memakan waktu yang lama akan menyebabkan tidak sesuai dengan spesifikasi yang ditentukan. Selain itu, aplikasi dari beberapa macam 
perkerasan jalan belum tentu bisa diterapkan pada topografi jalan yang ada di Kabupaten Trenggalek khususnya di Dataran Tinggi. Dengan keterbatasan anggaran yang tersedia, pemerintah daerah harus bisa memanfaatkan dana tersebut secara tepat untuk mendapatkan pelayanan jalan yang mantap. Saat ini Pemerintah Kabupaten Trenggalek telah melakukan pembangunan dan pemeliharaan jalan dengan menggunakan beberapa tipe perkerasan. Beberapa tipe perkerasan yang digunakan yaitu perkerasan kaku beton tak bertulang dan beton bertulang, sedangkan perkerasan lentur yang digunkana yaitu Asphalt Concrete Leveling (ACL) dan lapisan penetrasi $5 \mathrm{~cm}$ (lapen). Untuk memilih jenis perkerasan di dataran tinggi/pegunungan harus memperhatiakan beberapa kriteria. Secara teknis pemilihan tipe perkerasan berdasarkan nilai daya dukung tanah yang dinyatakan dengan nilai California Bearing Ratio (CBR), semakin tinggi nilai CBR maka akan dipilih perkerasan lentur dan semakin rendah nilai CBR tanah maka perkerasan yang dipilih adalah perkerasan kaku. Namun pemilihan tipe perkerasan berdasarkan nilai CBR tanah di dataran tinggi Kabupaten Trenggalek belum tentu bisa diterapkan.

Oleh karena itu diperlukan kriteria yang tepat untuk memilih tipe perkerasan yang tepat. Beberapa kriteria ini bisa didasarkan sifat dan karakteristik dari tipe perkerasan yang digunakan maupun dari karakteristik lokasi dan kondisi proyek. Makalah ini membahas tentang penentuan kriteria pemilihan perkerasan jalan yang tepat pada dataran tinggi di Kabupaten Trenggalek untuk memberikan masukan kepada dinas terkait yang menangani penanganan jalan pada dataran tinggi di Kabupaten Trenggalek

\section{STUDI PUSTAKA}

\section{Perkerasan Jalan}

Perkerasan jalan merupakan lapisan perkerasan yang terletak diantara lapisan tanah dasar dan roda kendaraan, yang berfungsi memberikan pelayanan kepada sarana transportasi dan selama masa pelayanannya diharapkan tidak terjadi kerusakan yang berarti. Material utama pembentuk lapisan perkerasan jalan adalah agregat, yaitu 90-95\% dari berat campuran perkerasan. Bahan pengikat seperti aspal dan semen digunakan sebagai bahan pengikat agar terbentuk perkerasan kedap air. Perkerasan dengan mempergunakan aspal sebagai bahan pengikat disebut perkerasan lentur, dan perkerasan dengan mempergunakan semen sebagai bahan pengikat disebut perkerasan kaku. Lapisan perkerasan dengan menggabungkan perkerasan kaku dan perkerasan lentur dinamakan perkerasan komposit [1].

\section{Jenis Perkerasan}

\section{Perkerasan Lentur}

Jenis jenis campuran aspal panas yang banyak dipakai sebagai lapis perkerasan diantaranya [2]:

1. Lapis aspal beton (Laston, AC)

Laston adalah suatu lapis permukaan yang terdiri dari campuran aspal keras dan agregat yang bergradasi menerus dicampur, dihamparkan dan dipadatkan dalam kondisi panas dan suhu tertentu. Laston bersifat kedap air, mempunyai nilai struktur, awet, kadar aspal berkisar $4-7 \%$ terhadap berat campuran dan dapat digunakan untuk lalu lintas ringan, sedang sampai berat. Kimpraswil (2000) membagi lapis aspal beton menjadi 3 macam campuran, yaitu laston lapis aus (AC-WC), laston lapis pengikat ( $\mathrm{AC}-\mathrm{BC}$ ), laston lapis pondasi (AC-base), dengan ukuran maksimum agregat masing masing campuran adalah $19 \mathrm{~mm}, 25,4 \mathrm{~mm}$ dan $37,5 \mathrm{~mm}$.

2. Lapis tipis aspal beton (Lataston, HRS)

Lataston atau Hot Rolled Sheet (HRS) yang bergradasi senjang ini adalah campuran aspal dengan kadar aspal yang relatif tinggi daripada jenis laston. Maksud dari penggunaan kadar aspal yang tinggi adalah agar perkerasan mempunyai fleksibilitas tinggi, awet dan tahan terhadap kelelahan. Lataston terdiri dari 2 macam, yaitu: Lataston lapis pondasi (HRS-base) dan lataston lapis permukaan (HRS-wearing course) dan ukuran maksimum agregat masing - masing campuran adalah $19 \mathrm{~mm}$. Lataston lapis pondasi (HRS-base) mempunyai gradasi yang lebih kasar daripada lataston lapis permukaan (HRS-wearing course).

3. Latasir (sand sheet)

Lapis tipis aspal pasir (latasir) adalah lapis penutup yang terdiri dari aspal keras dan pasir alam yang bergradasi menerus, dicampur dan dipadatkan, pada suhu tertentu dengan tebal setelah dipadatkan $1-2$ $\mathrm{cm}$. Latasir ini berfungsi sebagai lapis penutup, lapis aus dan dapat memberikan permukaan jalan yang rata dan halus. Latasir bersifat kedap air dan kenyal, tidak memiliki nilai struktur, tahan terhadap keausan akibat lalu lintas dan pengaruh cuaca. Campuran ini digunakan pada jalan dengan lalu lintas ringan, khususnya pada daerah dimana agregat kasar sulit diperoleh. Campuran ini ketahanannya rendah terhadap alur (rutting) karena itu tidak boleh digunakan untuk lapisan yang tebal, pada jalan lalu lintas berat dan pada daerah tanjakan.

4. Lapis Penetrasi Macadam (Lapen)

Lapis penetrasi macadam (lapen) adalah lapis perkerasan yang terdiri dari agregat pengunci bergradasi seragam. Setelah agregat pengunci dipadatkan. Lapen sesuai digunakan untuk lalu-lintas ringan sampai dengan sedang.

Tanah dalam kondisi alam / apa adanya jarang sekali mampu mendukung beban berulang dari kendaraan tanpa mengalami kerusakan dan terdeformasi. Sehingga adanya perkerasan sangat diperlukan untuk melindungi tanah dari beban yang diterima. Susunan perkerasan jalan biasanya disusun dengan cara paling lemah dibagian bawah kemudian diikuti bagian yang lebih kuat dibagian atasnya. Hal ini terkait dengan penekanan biaya, yang mana sesuai prinsip rekayasa teknik yaitu dengan pengeluaran biaya yang sedikit namun didapatkan hasil konstruksi yang maksimal/kuat [3].

Suatu jalan sangat memerlukan adanya perkerasan agar nyaman dan mudah untuk dilalui, sehingga fungsi perkerasan jalan diantaranya yaitu :

1. Untuk memberikan permukaan rata/halus bagi pengendara; 


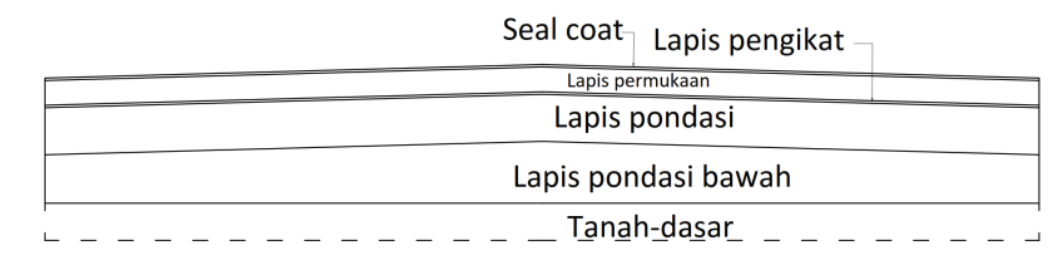

Gambar 1. Potongan Melintang Kontruksi Perkerasan Lentur

Sumber : Hardiyatmo, 2015. [4]

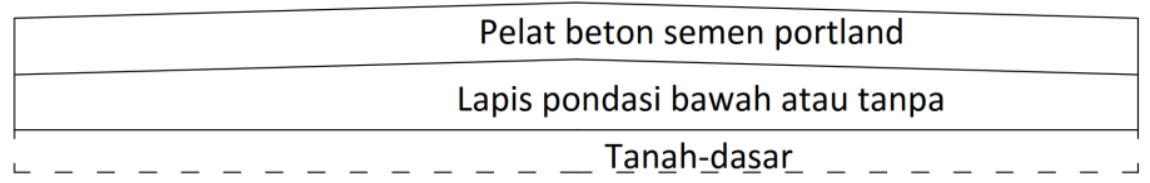

Gambar 2. Potongan Melintang Perkerasan Kaku Tipikal

Sumber : Hardiyatmo, 2015. [4]

2. Untuk mendistribusikan beban kendaraan di atas formasi tanah secara memadai, sehingga melindungi tanah dari tekanan yang berlebihan;

3. Untuk melindungi formasi tanah dari pengaruh buruk perubahan cuaca.

Secara umum potongan melintang konstruksi perkerasan lentur ditunjukkan pada Gambar 1.

\section{Perkerasan Kaku}

Pemilihan perkerasan tidak hanya bergantung pada lalu lintasnya saja namun juga memperhitungkan sifat tanah serta kondisi sekitar jalan. Jalan dengan lalu lintas yang padat maka karakteristiknya berbeda dengan $\mathrm{j}$

alan yang lalu lintasnya sepi, demikian juga halnya dengan sifat sifat tanah yang dibawahnya. Untuk kondisi alam yang curah hujan tinggi serta keadaan sekitar (alinyemen, kondisi drainase dan lain-lain) juga merupakan hal yang penting untuk penentuan karateristik konstruksi [3]. Berikut macam - macam perkerasan kaku

1. Jointed Unreinfored Concrete Pavement (JUCP) atau Perkerasan Beton Semen Bersambung Tanpa Tulangan (BBTT). Jenis perkerasan jalan beton semen yang dibuat tanpa tulangan dengan ukuran pelat mendekati bujur sangkar dimana panjang dari pelatnya dibatasi oleh adanya sambungan sambungan melintang.

2. Jointed Reinforced Concrete Pavement (JRCP) atau Perkerasan Beton Semen Bersambung Dengan Tulangan (BBDT), adalah jenis perkerasan jalan beton semen yang dibuat dengan tulangan, dengan ukuran plat berbentuk empat persegi panjang dimana panjang dari pelatnya dibatasi oleh adanya sambungansambungan melintang. Panjang pelat dari jenis perkerasan ini berkisar antara 8-15 m.

3. Continoussly Reinforced Concrete Pavement (CRCP) atau Perkerasan Beton Semen Menerus Dengan Tulangan (BMDT). Jenis perkerasan jalan beton semen yang dibuat dengan tulangan dan dengan panjang plat yang menerus yang hanya dibatasi oleh adanya sambungan - sambungan muai melintang. Panjang pelat dari jenis perkerasan ini lebih besar dari $75 \mathrm{~m}$.

4. Prestressed Concrete Pavement atau Perkerasan Beton Semen Prategang. Jenis perkerasan jalan beton semen menerus, tanpa tulangan biasa tapi menggunakan kabel-kabel pratekan guna mengurangi pengaruh susut, muai dan lenting akibat perubahan temperatur dan kelembaban.

5. Steel Fibre Concrete Pavement atau Perkerasan Beton Semen Bertulangan Serat Baja. Jenis perkerasan jalan beton semen menerus, tanpa tulangan biasa tapi menggunaka serat fibre baja.

Berikut Gambar 2 menunjukkan konstruksi beton terdiri atas 3 lapisan yaitu lapisan tanah dasar (subgrade), lapisan lantai kerja (cement treated subbase) dan beton.

\section{Elemen Geometrik Jalan}

Eleman geometrik jalan raya yang utama adalah alinyemen horisontal, alinyemen vertikal, alinyemen pada persimpangan jalan dan alinyemen pada tikungan [3].

\section{Alinyemen Horisontal}

Alinyemen horisontal adalah proyeksi sumbu jalan pada bidang horisontal. Alinyemen horisontal dikenal juga dengan nama situasi jalan atau trase jalan. Alinyemen horisontal terdiri dari garis-garis lurus, yang dihubungkan dengan garis-garis lengkung. Garis lengkung tersebut dapat terdiri dari busur lingkaran ditambah dengan lengkung peralihan atau busur-busur peralihan saja ataupun busur lingkaran saja [3].

\section{Alinyemen Vertikal}

Alinyemen vertikal adalah perpotongan bidang vertikal dengan bidang permukaan perkerasan jalan memalui sumbu jalan, yang umumnya disebut dengan profil/penampang memanjang jalan. Perencanaan alinyemen vertikal sangat dipengaruhi oleh beberapa hal, antara lain (Saodang, 2010):

- Kondisi tanah dasar

- Keadaan medan

- Fungsi jalan

- Muka air banjir

- Kelandaian yang masih memungkinkan

\section{Kriteria}

Dalam proses pengambilan keputusan pada beberapa pada beberapa alternatif maka akan dibutuhkan adanya kriteria. Kriteria digunakan sebagai alat ukur untuk mengukur tingkat pencapaian tujuan, karena kriteria 


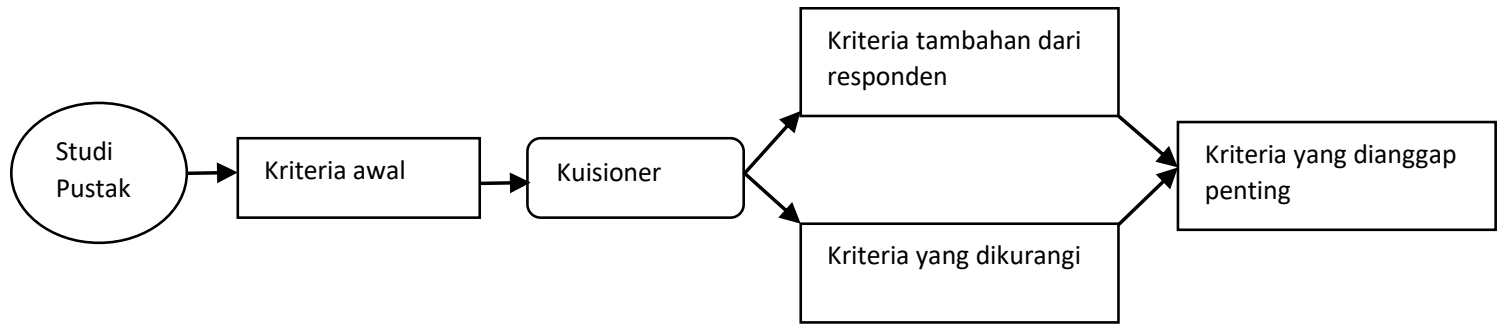

Gambar 3. Diagram alir penelitian

menunjukkan definisi dari suatu masalah dalam bentuk yang konkrit.

Kriteria adalah standart penentuan atau atuan-aturan dasar yang mana alternatif keputusan-keputusan diurutukan menurut keinginan kriteria itu sendiri, atau dengan kata lain kriteria adalah suatu istilah umum yang meliputi konsep-konsep dari atribut dan sasaran [5].

Faktor-faktor yang berpengaruh terhadap kelayakan perkerasan diantaranya ada faktor teknis, faktor non teknis dan biaya [6]. Faktor teknis merupakan faktor yang paling dominan untuk mengukur kelayakan jalan. Faktorfaktor teknis diantaranya daya tahan terhadap cuaca, daya tahan terhadap pergerakan tanah dan daya tahan terhadap perubahan lalu lintas. Untuk faktor non teknis yang mempengaruhi kelayakan suatu perkerasan jalan yaitu faktor jangka waktu perawatan yang berkaitan dengan cepat atau lamanya suatu kontruksi membutuhkan perbaikan. Sedangkan ketersediaan sumber daya berkaitan dengan ketersediaan dana. Kedua faktor non teknis mengindikasikan bahwa sesedikit mungkin perawatan dan perbaikan yang dilakukan berarti konstruksi jalan dianggap lebih baik dan ketersediaan sumber daya khususnya dana merupakan faktor yang sangat menentukan suatu konstruksi dipilih untuk dibangun atau tidak. Karena pada dasarnya dana selalu menjadi kendala ketersediaan anggaran pembangunan jalan di Indonesia. Sementara faktor lain yang penting diperhatikan adalah masalah kenyamanan permukaan konstruksi jalan. Faktor ini penting karena berkaitan dengan kenyamanan pengguna setelah kontruksi selesai dibangun. Dalam studi ini, faktor kenyamaan juga lebih diunggulkan disbanding faktor kemudahan dalam pembangunan [7].

Drainase adalah faktor penting yang harus dipertimbangkan dalam perancangan perkerasan, karena memiliki konstribusi $(0,7 \mathrm{~s} / \mathrm{d} 1,2)$ dalam penentuan tebal lapis konstruksi perkerasan. Perancangan saat ini sering terdapat lapis pondasi yang tidak memiliki sistem drainase yang bagus, sehingga pada saat air berada di dalam lapis pondasi, bersamaan dengan jumlah beban kendaraan berat, akan timbul kerusakan konstruksi perkerasan [1].

\section{PENGUMPULAN DATA}

Infrastruktur jalan pada dataran tinggi di Kabupaten Trenggalek banyak mengalami kerusakan. Rusaknya infrastruktur jalan di Kabupaten Trenggalek salah satunya bisa disebabkan oleh pemilihan tipe perkerasan yang kurang tepat. Pemilihan tipe perkerasan yang kurang tepat dimaksud yaitu perkerasan tersebut tidak bisa dilaksanakan karena kondisi medan, cepat terjadi kerusakan sebelum umur rencana habis, pemeliharaan kerusakan jalan yang sulit, ketersediaan material yang terbatas, keselamatan dan kenyamanan pengguna jalan tidak terpenuhi. Infrastruktur jalan yang ada di Kabupaten Trenggalek pada dataran tinggi berbatasan langsung dengan tanah milik perhutani dan tanah warga. Lebar badan jalan yang ada saat ini 2,5 m sampai dengan $4 \mathrm{~m}$. Perkerasan yang digunakan di Kabupaten Trenggalek yaitu beton tak bertulang, beton tak bertulang dua sisi, beton bertulang, acl tebal $4 \mathrm{~cm}$ dan lapen tebal $5 \mathrm{~cm}$.

Metode yang dilakukan pada penentuan kriteria awal dalam pemilihan tipe perkerasan pada dataran tinggi di Kabupaten Trenggalek adalah pengumpulan data sekunder dan data primer. Pengumpulan data primer yang dilakukan dengan survai wawancara kepada rsponden yang memiliki kompetensi dan berpengalaman dalam melakukan penanganan jalan pada dataran tinggi di Kabupaten Trenggalek. Survai wawancara dilakukan pada bulan September 2017. Responden yang diwawancarai sebanyak 14 responden terdiri dari pejabat di Dinas Pekerjaan Umum dan Penataan Ruang Kabupaten Trenggalek, konsultan perencana, konsultan pengawas dan penyedia barang/jasa. Kriteria awal yang ditawarkan kepada responden berjumlah 6 kriteria berdasarkan studi pustaka sebelumnya. Untuk validasi pada penelitian ini dalam menentukan kriteria apa saja yang dipentingkan pada pemeliharaan jalan pada dataran tinggi di Kabupaten Trenggalek diharapkan responden memberikan tambahan kriteria ataupun mengurangi kriteria yang ditawarkan beserta alasannya. Kriteria akan dikurangi apabila minimal 3 responden menyatakan kriteria tersebut tidak dipentingkan. Dari kriteria yang ditawarkan, kriteria tambahan dan kriteria yang dikurangi akan dilakukan sintesa untuk memastikan kriteria yang dipentingkan memiliki arti, maksud dan sesuai dengan kenyataan dilapangan. Berikut diagram alir penelitian penentuan kriteria ditunjukkan pada Gambar 3.

\section{ANALISIS PENELITIAN}

\section{Kondisi Umum Infrastruktur Jalan Kabupaten Trenggalek}

Kabupaten Trenggalek dikelompokkan menjadi dua wilayah yaitu dataran tinggi dan dataran rendah. Pengelompokan ini untuk membedakan harga satuan dan jenis konstruksi infrastruktur yang akan digunakan. Dataran tinggi terdiri dari enam kecamatan dengan panjang jalan $600,233 \mathrm{~km}$. Infrastruktur jalan pada dataran tinggi di Kabupaten Trenggalek banyak 
Tabel 1. Panjang ruas jalan pada dataran tinggi di Kabupaten Trenggalek.

\begin{tabular}{|c|c|c|c|c|c|c|}
\hline \multirow{2}{*}{ KECAMATAN } & \multirow{2}{*}{$\begin{array}{c}\text { PANJANG } \\
\text { JALAN } \\
\text { ( KM ) }\end{array}$} & \multicolumn{4}{|c|}{ KONDISI TAHUN 2016} & \multirow{2}{*}{ KETERANGAN } \\
\hline & & BAIK & SEDANG & RUSAK & RUSAK BERAT & \\
\hline PANGGUL & 76.640 & 45.140 & 14.705 & 13.284 & 3.511 & Perbedaan angka antara \\
\hline MUNJUNGAN & 85.653 & 42.170 & 14.009 & 16.926 & 12.548 & Ruas-ruas Jalan \\
\hline WATULIMO & 109.639 & 76.613 & 19.290 & 11.916 & 1.820 & Kabupaten dengan \\
\hline DONGKO & 73.051 & 42.170 & 14.455 & 10.868 & 5.558 & Ruas-ruas Jalan \\
\hline PULE & 94.984 & 65.855 & 16.636 & 9.987 & 2.506 & Kecamatan Jalan \\
\hline KAMPAK & 50.300 & 36.510 & 6.742 & 4.695 & 2.353 & Kabupaten menjadi \\
\hline SURUH & 55.366 & 31.666 & 12.497 & 6.922 & 4.281 & Jalan Nasional, jalan \\
\hline BENDUNGAN & 54.600 & 21.950 & 13.395 & 10.985 & 8.270 & desa menjadi jalan \\
\hline JUMLAH & 600.233 & 362.074 & 111.729 & 85.583 & 40.847 & kewenangan kabupaten \\
\hline
\end{tabular}

Sumber: Dinas Pekerjaan Umum dan Penataan Ruang Kabupaten Trenggalek, 2017

Tabel 2. Kondisi permukaan jalan di Kabupaten Trenggalek tahun 2016

\begin{tabular}{ccccccc}
\hline & PANJANG & \multicolumn{5}{c}{ KONDISI } \\
\cline { 3 - 6 } PERMUKAAN & JALAN & \multirow{2}{*}{ BAIK } & SEDANG & RUSAK & $\begin{array}{c}\text { RUSAK } \\
\text { BERAT }\end{array}$ & TOTAL \\
& $(\mathrm{Km})$ & $(\mathrm{Km})$ & $(\mathrm{Km})$ & $(\mathrm{Km})$ & $(\mathrm{Km})$ & $(\mathrm{Km})$ \\
\hline ASPAL & 892.762 & 573.354 & 176.634 & 90.788 & 51.986 & 892.762 \\
BETON & 38.468 & 25.031 & 11.000 & 2.437 & 0.000 & 38.468 \\
TOTAL & 931.230 & 598.385 & 187.634 & 93.225 & 51.986 & 931.230 \\
\hline
\end{tabular}

mengalami kerusakan. Keterbatasan anggaran menjadi kendala dalam penanganan jalan. Panjang jalan tiap kecamatan pada dataran tinggi dapat dilihat pada Tabel 1 .

Di dataran tinggi tidak semua alat berat untuk penangan jalan bisa digunakan/beroprasi. Tidak sedikit jalan yang baru saja diperbaiki cepat terjadi kerusakan. Pada saat hujan sering terjadi kecelakaan, terutama pada jalan yang memiliki kelandaian memanjang (tanjakan/turunan). Pemilihan menggunakan perkerasan lentur dapat mengurangi selip namun alat terkendala dengan kemampuan alat berat dan abrasi oleh air. Pemilihan perkerasan kaku yang mudah dilaksanakan dan tidak terpengaruh cuaca membuat jalan menjadi licin dan tidak nyaman saat musim penghujan karena ditumbuhi lumut. Hal ini disebabkan di dataran tinggi yang lembab dan dingin serta keterbatasan jumlah pekarya jalan yang bertugas sebagai pemelihara jalan rutin. AMP terdekat dengan Kabupaten Trenggalek yang beroprasi ada di Kabupaten Blitar dan Kabupaten Kediri. Untuk perkerasan kaku beton menggunakan beton cor setempat karena apabila menggunakan ready mix, mobil ready mix tidak bisa mencapai lokasi.

\section{Alternatif Tipe Perkerasan}

Saat ini di Kabupaten Trenggalek menggunakan perkerasan lentur dan perkerasan kaku, pemilihan perkerasan ini didasarkan oleh beberapa kriteria yang dianggap penting. Perkerasan yang digunakan pada dataran tinggi diantaranya:

1. Perkerasan Beton Bertulang K225 tebal $20 \mathrm{~cm}$.

Perkerasan beton K225 dengan ketebalan $20 \mathrm{~cm}$ dengan cor setempat. Pada perkerasan ini dilakukan penulangan menggunakan besi wiremesh ukuran M10 dan diberi tie bar dan dowel. Peralatan utama yang digunakan yaitu molen, alat ukur dan alat angkut.

2. Perkerasan beton K 225 tak bertulang tebal $15 \mathrm{~cm}$ Perkerasan beton tak bertulang K 225 tebal $15 \mathrm{~cm}$ dengan cor setempat secara menerus menggunakan peralatan utama molen, alat ukur, dump truck/pick-up.

3. Rabat beton $\mathrm{K} 225$ dua sisi tebal $15 \mathrm{~cm}$

Perkerasan beton tak bertulang K 225 tebal $15 \mathrm{~cm}$ dengan cor setempat secara menerus menggunakan peralatan utama molen, alat ukur, dump truck/pick-up. Lebar perkerasan $80 \mathrm{~cm}$ pada sisi kanan dan kiri, bagian tengah lebar $80 \mathrm{~cm}$.

4. ACL tebal $4 \mathrm{~cm}$

ACL tebal $4 \mathrm{~cm}$ merupakan campuran hotmix dimana peralatan utama yang digunakan Finisher, tire roller, tandem roller dan dump truck. Campuran aspalt panas dari AMP dibawa dengan dump truck dan oleh dumptruck dituang pada finisher untuk meratakan hotmix, kemudian dibelakang finisher campuran aspalt panas dari finisher yang telah digelar dipadatkan menggunakan tie roller dan tandem roller.

5. Lapen tebal $5 \mathrm{~cm}$

Lapen dengan tebal $5 \mathrm{~cm}$ merupakan lapisan lentur dimana aspalt dipanaskan di lokasi pekerjaan dan agreagat batu pecah dihampar dilokasi pekerjaan. Kemudian dipadatkan menggunakan tandem roller 810 ton dengan jumlah lintasan tertentu.

Kondisi jenis permukaan perkerasan di Kabupaten Trenggalek dapat dilihat pada Tabel 2. 


\section{Karakteristik Jalan Pada Dataran Tinggi di Kabupaten Trenggalek}

Topografi wilayah jalan pada dataran tinggi di Kabupaten Trenggalek dibedakan menjadi 3 wilayah yaitu wilayah datar, wilayah perbukitan dan wilayah pegunungan. Kondisi geometri jalan pada dataran tinggi di Kabupaten Trenggalek digambarkan dengan potongan melintang jalan, potongan memanjang dan tampak atas. Potongan melintang jalan dibagi menjadi 4 macam yaitu jalan diantara dataran, jalan diatara tebing, jalan diantara jurang dan jalan diatara tebing dan jurang. Dilihat dari potongan memanjang jalan pada dataran tinggi di Kabupaten Trenggalek dibagi menjadi 3 yaitu datar, menanjak/menurun landai dan menanjak/menurun curam. Sedangkan dilihat dari tampak atas dibagi menjadi dua yaitu jalan dengan belokan yang tajam dan jalan dengan belokan yang landai.

\section{Penentuan Kriteria}

Kriteria Yang Ditawarkan Kepada Responden

Dari kriteria kriteria yang telah ditawarkan diantaranya ada enam kriteria yaitu:

1. Keselamatan pengguna jalan

- Keselamatan pengguna jalan ini diartikan sebagai daya cengkram pengereman terhadap roda tinggi sehingga tidak mudah tergelincir.

- Permukaannya kasar dan tidak licin sehingga pengguna jalan terjamin keselamatannya saat memanfaatkan jalan.

2. Kenyamanan pengguna jalan

- Jalan nyaman untuk dilalui, tidak bergelombang, tidak ada lobang, tidak amblas dan getaran pada sumbu roda minim.

- Jalan yang dibangun segera bisa dimanfaatkan/digunakan.

3. Biaya konstruksi

- Untuk melakukan penghematan biaya, dengan biaya yang besarnya sama namun panjang jalan yang dihasilkan lebih panjang.

4. Kemudahan pelaksanaan konstruksi jalan

- Dalam pelaksanaannya tidak mengalami kesulitan baik alat maupun pekerja yang melaksanakan. Alat dan material dapat dioperasikan dan dapat mencapai lokasi pekerjaan.

- Mudah untuk mencapai spesifikasi yang ditetapkan oleh direksi atau dinas terkait

5. Perawatan setelah masa pemeliharaan habis

- Mudah dilakukan pemeliharaan apabila terjadi kerusakan setelah masa pemeliharaan oleh kontraktor berakhir.

- Diharapkan kemudahan partisipasi masyarakat/pemerintah desa setempat untuk melakukan perbaikan jalan.

6. Ketersedian material

- Kemudahan untuk mendapatkan bahan material konstruksi jalan sepanjang tahun.

Kriteria Tambahan dan Pengurangan Dari Hasil Wawancara

Dari hasil survey wawancara dengan responden, beberapa responden menambahkan beberapa kriteria disertai beberapa alasan pentingnya menambahkan kriteria tersebut. Dari ke 14 responden ada 11 responden yang menambahkan kriteria. Dari ke 11 kriteria yang ditambahkan dengan alasannya, 3 kriteria sama. Sehingga dapat dikelompokkan menjadi 9 kriteria tambahan. Sedangkan 3 responden menyatakan ketersedian material bukan termasuk kritria yang dipentingkan. Dari ke 9 kriteria tambahan beserta alasannya diantaranya;

1. Situasi dan kondisi lokasi pekerjaan

- Situasi dan kondisi yang dimaksud yaitu kemudahan bangunan pelengkap seperti drainase untuk dibangun.

- keadaan lingkungan ruang milik jalan sisi tepi jalan seperti tebing, dataran atau jurang.

- Kemudahan alat dan material untuk mencapai lokasi pekerjaan.

- Tanjakan/turunan.

- Situasi dan kondisi ruang milik jalan.

2. Daya dukung tanah

- Daya dukung tanah merupakan kestabilan tanah dasar, apakah tanah dasar sudah seatle/mantap dan tidak mudah amblas.

- Perkerasan apa yang sebelumnya digunakan.

- Kondisi kestabilan tanah antar wilayah di Trenggalek tidak sama.

3. Umur rencana

- Umur rencana yang panjang akan membuat jalan tidak mudah rusak, sebagai misal penggunaan beton umur rencana bisa mencapai 40 tahun, sedangkan perkerasa lentur hanya sampai 25 tahun.

4. Curah hujan

- Pada saat curah hujan tinggi pekerjaan menggunakan perkerasan beton sangat bagus karena terjadi pengerasan beton secara lambat dan kandungan air dalam beton tidak mudah hilang, sehingga spesifikasi yang telah ditentukan dapat tercapai.

- Apabila pengerjakan perkerasan lentur/aspal dikerjakan pada saat musim penghujan maka aspal akan mengalami penurunan suhu secara tiba-tiba, sehingga spesifikasi yang telah ditetapkan akan sulit tercapai.

5. Topografi

- Topografi yang dimaksud disini merupakan kondisi lingkungan sekitar jalan dan akses menuju lokasi proyek.

6. Lalu Lintas Harian (LHR)

- LHR (lalu lintas harian rata-rata) merupakan jumlah kendaraan yang melintas tiap harinya.

7. Ketahanan terhadap gerusan air

- Seringkali pada saat musim penghujan di daerah pegunungan, drainase yang ada tidak bisa menampung jumlah debit air, sehingga air mengalir di badan jalan.

- Banyak jalan di dataran tinggi pada Kabupaten Trenggalek tidak memiliki sistem drainase.

8. Akses menuju lokasi pekerjaan

- Untuk pekerjaan menggunakan hotmix, minimal memiliki tiga alat berat diantaranya finisher, tendem roller dan tie roller. Dimana untuk mencapai lokasi pekerjaan dilakukan mob demod alat berat, namun ada beberapa lokasi yang tidak bisa dilalui truk trailer maupun subloader. 
- Material bisa sampai ke lokasi dengan menggunakan minimal pick-up

9. Permintaan pemerintah setempat (desa)

- Permintaan desa setempat untuk memilih perkerasan tertentu karena dianggap apabila menggunakan perkerasan yang sama dengan sebelumnya, jalan cepat rusak.

Setelah dilakukan wawancara dengan responden, dari ke enam kriteria yang ditawarkan ada kriteria yang dihilangkan, karena 3 responden menyatakan pada kuisioner bahwa kriteria ketersedian material tidak perlu dihilangkan yaitu:

1. Ketersedian material

- Material untuk perkerasan kaku sangat mudah didapatkan.

- Di dataran tinggi saat ini di Kabupaten Trenggalek banyak berdiri usaha crusser/pecah batu, dimana mengahsilkan agregat dengan berbagai ukuran.

- Dalam kurun waktu 10 tahun terakhir tidak pernah ada terjadinya putus kontrak kerja karena sulitnya mendapat material.

Sintesa Kriteria Dari yang Ditawarkan dan Hasil Wawancara

Dari kriteri yang ditawarkan kepada responden dan tambahan dari hasil wawancara dengan responden terdapat beberapa kesamaan alasan. Sehingga dari kriteria yang ditambahkan dan pengurangan diambil beberpa kriteria yang memiliki arti, maksud dan sesuai dengan kenyataan dilapangan diantaranya;

1. Keselamatan pengguna jalan

- Keselamatan pengguna jalan ini diartikan sebagai daya cengkram pengereman terhadap roda tinggi sehingga tidak mudah tergelincir.

- Tidak mudah selip saat hujan dan saat pengereman.

- Permukaannya kasar dan tidak licin sehingga pengguna jalan terjamin keselamatannya saat memanfaatkan jalan.

2. Kenyamanan pengguna jalan

- Jalan nyaman untuk dilalui, tidak bergelombang, tidak ada lobang, tidak amblas dan getaran pada sumbu roda minim.

- Jalan yang dibangun segera bisa dimanfaatkan/digunakan.
3. Biaya konstruksi

- Untuk melakukan penghematan biaya, dengan biaya yang besarnya sama namun panjang jalan yang dibangun lebih panjang.

4. Situasi dan kondisi lokasi pekerjaan

- Dalam pelaksanaannya tidak mengalami kesulitan baik alat maupun pekerja yang melaksanakan. Alat dapat dioperasikan sesuai dengan persyaratan yang ditetapkan dan material dapat mencapai lokasi proyek. Sehingga spesifikasi yang dipersyaratkan dapat tercapai.

- Keadaan ruang milik jalan, dimana dilihat kondisi batas sisi paling tepi jalan. Sehingga apabila memerlukan bangunan pelengkap bisa dilaksanakan (drainase, tembok penahan tebing dan tembok penahan jalan) dan kelandaian memanjang.

5. Perawatan setelah masa pemeliharaan habis

- Mudah dilakukan pemeliharaan apabila terjadi kerusakan setelah masa pemeliharaan oleh konstraktor habis.

- Diharapkan kemudahan partisipasi masyarakat/pemerintah desa setempat untuk melakukan perbaikan jalan.

- Umur perkerasan lebih lama

6. Daya dukung tanah

- Daya dukung tanah merupakan kestabilan tanah dasar, apakah tanah dasar sudah seatle/mantap dan tidak mudah amblas dan apakah sebelum dilakukan perkerasan tanah sudah ada perkerasannya apa belum.

- Kondisi kestabilan tanah antar wilayah di Trenggalek tidak sama.

7. Ketahanan perkerasan terhadap gerusan air

- Seringkali pada saat musim penghujan di daerah pegunungan, drainase yang ada tidak bisa menampung jumlah debit air, sehingga air mengalir di permukaan badan jalan, karena air dari pegunungan mengalir ke bawah.

- Banyak jalan di dataran tinggi pada Kabupaten Trenggalek tidak memiliki sistem drainase karena jalan lebarnya $4 \mathrm{~m}$ dan berbatasan langsung dengan tanah milik perhutani, sehingga air hujan melimpas ke permukaan badan jalan

- Dalam kondisi tertentu (hujan) pada

Tabel 3. Bentuk form kuisioner

\begin{tabular}{|c|c|}
\hline Kriteria usulan & Keterangan \\
\hline 1. Keselamatan pengguna jalan & \\
\hline 2. Kenyamanan pengguna jalan & \\
\hline 3. Biaya konstruksi & \\
\hline 4. Kemudahan pelaksanaan konstruksi jalan & \\
\hline 5. Perawatan setelah masa pemeliharaan habis & \\
\hline 6. Ketersedian material & \\
\hline Kriteria yang perlu ditambahkan & Keterangan \\
\hline 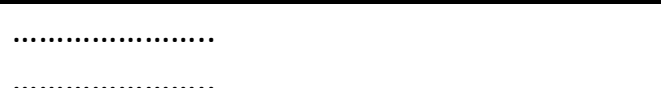 & …………............. \\
\hline Kriteria yang dihilangkan & Keterangan \\
\hline
\end{tabular}


tanjakan/turunan air hujan mengalir di permukaan badan jalan.

Untuk mendapatkan kriteria dilakukan wawancara dengan responde yang memiliki penanganan jalan pekerjaan pemeliharaan jalan pada dataran tinggi di Kabupaten Trenggalek. Berikut bentuk Tabel 3. untuk survei kriteria yang dipentingkan

\section{KESIMPULAN}

Hasil dari survey penentuan kriteria yang dipentingkan dalam memilih perkerasan yang tepat pekerjaan pemeliharaan jalan pada dataran tinggi di Kabupaten Trenggalek terhadap 14 responden yang memiliki pengalaman dan kompetensi dalam penanganan jalan. Dari usulan 6 kriteria mendapat tambahan 9 kriteria dan 1 kriteria yang dihilangkan. Dari usulan 6 kriteria, 9 kriteria tambahan dan 1 kriteria yang dihilangkan, disentesakan menjadi 7 kriteria.

- Usulan 6 kriteria adalah; keselamatan Penguna jalan, kenyamanan pengguna jalan, biaya konstruksi, kemudahan pelaksanaan konstruksi jalan, perawatan setelah masa pemeliharaan jalan habis, ketersediaan material.

- Hasil wawancara ada 9 kriteria tambahan yaitu; situasi dan kondisi lokasi pekerjaan, daya dukung tanah, umur rencana, curah hujan, topografi, LHR, ketahanan terhadap gerusan air, akses menuju lokasi pekerjaan, permintaan pemerintah setempat (desa). Satu Kriteria yang dihilangkan yaitu ketersedian material

- Hasil sintesa didapatkan 7 kritria yang dianggap penting yaitu; keselamatan pengguna jalan, kenyamanan pengguna jalan, biaya konstruksi, situasi dan kondisi lokasi pekerjaan, perawatan setelah masa pemeliharaan jalan habis, ketahanan terhadap gerusan air.

CATATAN. Makalah ini merupakan bagian dari Tesis Magister Manajemen Aset Infrastruktur dengan judul "Pemilihan Perkerasan Untuk Pekerjaan Pemeliharaan Jalan Pada Dataran Tinggi di Kabupaten Trenggalek”.

\section{DAFTAR PUSTAKA}

[1] Sukirman, S. (2003). Beton Aspal Campuran Panas. Edisi 1. Granit. Jakarta.

[2] Sukirman, S. (2010). Perencanaan Tebal Struktur Perkerasan Lentur. Nova. Bandung.

[3] Yamin, M. (2002). Campuran Aspal Panas. Nova. Bandung.

[4] Saodang, H. (2010). Konstruksi Jalan Raya, Cetakan ke-2. Nova. Bandung.

[5] Hardiyatmo, H.C. (2015). Pemeliharaan Jalan Raya, Cetakan ke-3. Gadjah Mada University Press, Anggota IKAPI. Yogyakarta.

[6] Malczewski, Jacek. (1999). GIS and Multricriteria Decision Analysis, University of Western Ontario. Canada.

[7] Wardi, N. dkk (2015), "Studi Kelayakan Jalan Perkerasan Kaku Dan Perkerasan Lentur", Jurnal JEnsitec : Vol 02|No.01, November 2015, hal 28-35.
[8] Apriyanto, Agus (2008). Perbandingan Kelayakan Jalan Beton dan Aspal Dengan Metode AHP (Studi Kasus Jalan Raya Demak-Godong). Tesis Pasca Sarjana. Universitas Diponegoro. Semarang. 